\title{
Analisa Kinerja Koneksi Jaringan Komputer Pada Universitas Islam Syekh-Yusuf Tangerang dengan QoS
}

\author{
Djamaludin $^{1)}$ dan Wina Septiana ${ }^{2 *}$ \\ Jurusan Teknik Informatika, Fakultas Teknik, Universitas Islam Syekh Yusuf, Jl. Mulana Yusuf No.10 \\ Tangerang Banten 15118, Indonesia \\ 1) djamaludin@unis.ac.id \\ ${ }^{2)}$ winaseptiana48@gmail.com
}

\begin{abstract}
Abstrak. Perkembangan Teknologi Jaringan Komputer dewasa ini sangat pesat hal ini memerlukan sebuah penanganan jaringan dengan kinerja yang sangat baik, melalui jurnal ini akan digambarkan analisa kinerja jeringan computer dengan menggunakan pengukuran kualitas layanan yang meliputi parameter jitter, throghput, packet loss, dan delay dengan menggunakan Biznet Speed Meter dan aplikasi Wireshark, dalam analisa ini menggunakan metode pengukuran dengan QoS (Quality of Service), dari analisa ini bisa menjadi masukan bagi Institusi untuk meningkatkan performance pelayanan Jaringan Komputer bagi civitas akademik Universitas Islam Syekh - Yusuf.
\end{abstract}

Kata kunci: analisa, jaringan, parameter jitter, speed meter, wireshark, quality of service

Abstract. The development of computer network technology today is very rapidly this requires a handling of the network with excellent performance, through this journal will be described performance analysis of computer rival by using service quality measurement that includes parameters jitter, throghput, packet loss, and delay using Biznet Speed Meter and Wireshark applications, in this analysis using the measurement method with QoS (Quality of Service), from this analysis can be an input for the Institution to improve the performance of Computer Network services for the academic community of Shaykh Islamic University - Yusuf.

Keywords: analysis, networking, parameters jitter, speed meter, wireshark, quality of service,

\section{Pendahuluan}

Perkembangan teknologi yang sangat pesat di era globalisasi saat ini telah memberikan banyak manfaat dan kemajuan diberbagai aspek sosial. Hal terpenting dalam perkembangan dan dalam penyelesaian dari berbagai masalah belakangan ini adalah bagaimana seseorang memperoleh data yang akurat, fleksibel dan mudah didapatkan. Hal ini tentunya memicu pemikiran manusia untuk menindak lanjuti akar masalah tersebut dengan sebuah jaringan yang mampu menghubungkan sebuah komputer dengan komputer lainnya.

Universitas Islam Syekh-Yusuf (UNIS) Tangerang adalah Perguruan Tinggi Pertama yang didirikan di Tangerang, berdiri tanggal 14 april 1966 dan merupakan salah satu pelopor pendidikan tinggi islam di Banten. Universitas Islam Syekh-Yusuf Tangerang ini beralamat di Jl. Maulana Yusuf No.10, Babakan,
Kec.Tangerang, Kota Tangerang, Banten 15118. Universitas Islam Syekh-Yusuf Tangerang pada saat ini sudah menggunakan jaringan komputer, koneksi jaringan computer menggunakan router dan switch sebagai koneksi jaringannya. Jaringan komputer merupakan sebuah kebutuhan yang semakin banyak digunakan. Secara umum yang disebut jaringan komputer adalah beberapa komputer yang saling berhubungan dan melakukan komunikasi satu dengan yang lain menggunakan perangkat keras jaringan (ethenet card, token ring, bridge, modem dan sebagainya). Komputer yang berada didalam suatu jaringan dapat melakuakn tukar menukar informasi atau data dengan komputer lain yang berada dalam jaringan tersebut.

Penelitian untuk pengukuran performance dari layanan jaringan internet yang meliputi parameter Quality of Service (QoS) yang terdiri dari Delay/latency, Jitter, Packet Loss, dan Throughput dilingkungan Universitas Islam 
Syekh-Yusuf. Sehingga diharapkan dari pengukuran ini diketahui bagaimana Quality of Service (QoS) dari jaringan internet di lingkungan Universitas Islam Syekh-Yusuf.

\section{Rumusan Masalah}

Berdasarkan latar belakang yang telah diuraikan diatas, maka masalah yang dapat dirumuskan adalah " Bagaimana menganalisa kinerja koneksi jaringan jaringan komputer pada Universitas Islam Syekh-Yusuf Tangerang?".

\section{Batasan Masalah}

Adapun batasan masalah pada penelitian ini yaitu "Menganalisa kinerja koneksi jaringan komputer dengan melakukan pengukuran pada parameter kualitas layanan yang meliputi parameter jitter, throghput, packet loss, dan delay dengan menggunakan Biznet Speed Meter dan aplikasi Wireshark pada Universitas Islam Syekh-Yusuf Tangerang.

\section{Tujuan Penelitian}

Adapun tujuan yang dicapai dalam penelitian ini adalah untuk menganalisa kinerja koneksi jaringan komputer dan agar mengetahui jumlah jitter, throughput, packet loss, dan delay pada Universitas Islam Syekh-Yusuf Tangerang.

\section{Pengertian Quality of Service (QoS)}

Quality of Service (QoS) merupakan metode pengukuran tentang seberapa baik jaringan dan merupakan suatu usaha untuk mendefinisikan karakteristik dan sifat dari satu servis. QoS digunakan untuk mengukur sekumpulan atribut kinerja yang telah dispesifikasikan dan diasosiasikan dengan suatu servis.

QoS mengacu pada kemampuan jaringan untuk menyediakan layanan yang lebih baik pada trafik jaringan tertentu melalui teknologi yang berbeda-beda. QoS menawarkan kemampuan untuk mendefinisikan atributatribut layanan jaringan yang disediakan, baik secara kualitatif maupun kuantitatif. Pada Tabel 1 diperlihatkan nilai persentase dari QoS.
Tabel 1. Presentase dan Nilai dari QoS

\begin{tabular}{rcc}
\hline Nilai & Persentase (\%) & Indeks \\
\hline $3,8-4$ & $95-100$ & Sangat Memuaskan \\
\hline $3-$ & $75-94,75$ & Memuaskan \\
3 & & \\
7 & & \\
9 & & \\
\hline $2-$ & & \\
2 & & \\
, & & \\
9 & & \\
9 & & \\
& & \\
\hline $1-$ & $25-74,75$ & \\
1 & \\
9 & \\
9 & \\
& & \\
\hline
\end{tabular}

\section{Bahan dan Metode:}

\section{Model Penelitian Quality of Service (QoS)}

Pada Gambar 1 diperlihatkan model penelitian QoS, yaitu sebagai metode penelitian didirikan atas asumsi bahwa teori dan praktik dapat secara tertutup diintegrasikan dengan pembelajaran dari hasil intervensi yang direncanakan setelah diagnosis yang rinci terhadap konteks masalahnya.

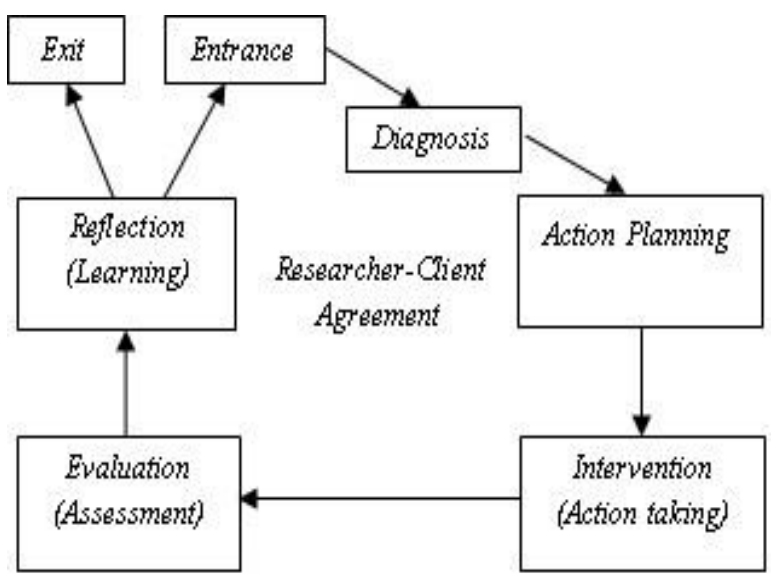

Gambar 1. Model Penelitian QoS

Model dari sistem monitoring QoS pada Gambar 2 yang digunakan dalam penelitian ini 
terdiri dari komponen monitoring application, QoS monitoring, monitor, dan monitored objects.

\section{Monitoring Application}

Monitoring application merupakan sebuah antarmuka bagi administrator jaringan. Komponen ini berfungsi mengambil informasi lalu lintas paket data dari monitor, menganalisanya dan mengirimkan hasil analisis kepada pengguna. Berdasarkan hasil analisis tersebut, seorang administrator jaringan dapat melakukan operasi-operasi yang lain.

\section{QoS Monitoring}

QoS monitoring menyediakan mekanisme monitoring QoS dengan mengambil informasi nilai-nilai parameter QoS dari lalu lintas paket data.

\section{Monitor}

Monitor mengumpulkan dan merekam informasi lalu lintas paket data yang selanjutnya akan dikirimkan kepada monitoring application. Monitor melakukan pengukuran aliran paket data secara waktu nyata dan melaporkan hasilnya kepada monitoring application.

\section{Monitored Objects}

Monitored objects merupakan informasi seperti atribut dan aktifitas yang dimonitor di dalam jaringan. Di dalam konteks QoS monitoring, informasi-informasi tersebut merupakan aliran-aliran paket data yang dimonitor secara waktu nyata. Tipe aliran paket data tersebut dapat diketahui dari alamat sumber (source) dan tujuan (destination) di layer-layer IP, port yang dipergunakan misalnya UDP atau TCP, dan parameter di dalam paket RTP.

Menurut informasi QoS yang dapat diperoleh, monitoring QoS dapat diklasifikasikan ke dalam dua kategori yaitu monitoring QoS dari ujung-ke-ujung (end-to-end QoS monitoring (EtE QM)) dan monitoring distribusi QoS per node (distribution monitoring (DM)). Di dalam EtE QM, monitoring QoS dilakukan dengan cara mengukur parameterparemeter QoS dari pengirim kepada penerima. Sedangkan di dalam DM, proses monitoring QoS dilakukan di segmen-segmen jalur pengiriman atau antara node-node tertentu yang dikehendaki di sepanjang jalur pengiriman paket data dapat dilihat pada Gambar 2.

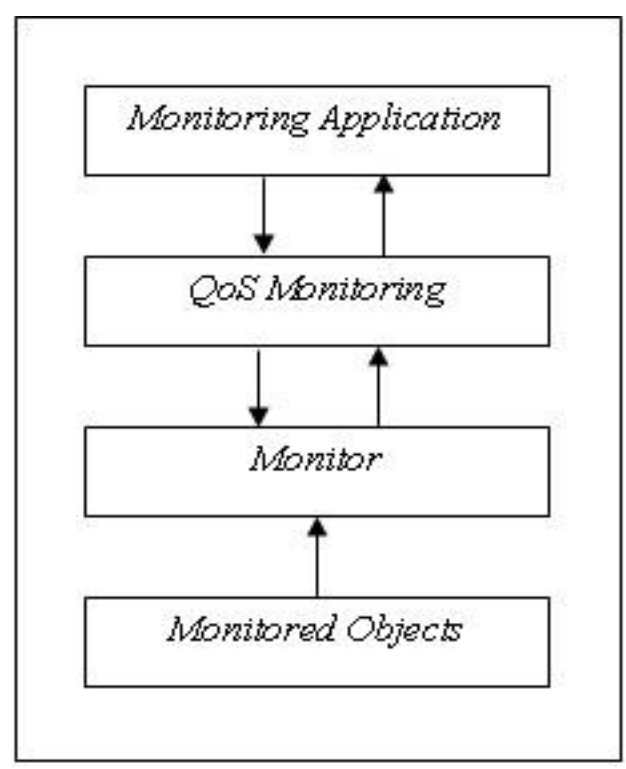

Gambar 2. Model Monitoring QoS Parameter Quality of Service (QoS)

Parameter - Parameter dari Quality of Service (QoS) terdiri dari:

\section{Throughput}

Throughput yaitu kecepatan (rate) transfer data efektif, yang diukur dalam bps (bit per second). Kategori Throughput diperlihatkan di Tabel 2.

Tabel 2. Kategori Throughput

\begin{tabular}{ccc}
\hline $\begin{array}{c}\text { Kategori } \\
\text { Throughput }\end{array}$ & $\begin{array}{c}\text { Throughput } \\
\text { (\%) }\end{array}$ & Indeks \\
\hline Sangat Bagus & $100 \%$ & 4 \\
\hline Bagus & $75 \%$ & 3 \\
\hline Sedang & $50 \%$ & 2 \\
\hline Jelek & $<25 \%$ & 1 \\
\hline
\end{tabular}

Untuk mengukur nilai Throughput digunakan Persamaan :

$$
\text { Throughput }=\frac{\text { paket data diterima }}{\text { lama pengamatan }}
$$

\section{Packet Loss}

Packet Loss merupakan suatu parameter yang menggambarkan suatu kondisi yang menunjukkan jumlah total paket yang hilang, dapat terjadi karena collision dan congestion pada jaringan. Pada Tabel 3 ditunjukkan nilai indeks dan kategori Packet Loss.

\begin{tabular}{ccc}
\hline $\begin{array}{c}\text { Kategori } \\
\text { Packet Loss }\end{array}$ & $\begin{array}{c}\text { Packet Loss } \\
(\%)\end{array}$ & Indeks \\
\hline Sangat Bagus & $0 \%$ & 4 \\
\hline Bagus & $3 \%$ & 3 \\
\hline Sedang & $15 \%$ & 2 \\
\hline Jelek & $25 \%$ & 1 \\
\hline
\end{tabular}


Tabel 3. Kategori Packet Loss

Untuk mengukur nilai Packet Loss digunakan Persamaan :

$$
\text { Packet loss }={ }_{A}^{Y} x 100
$$

Keterangan :

$\mathrm{Y}=$ packet data dikirim - packet data diterima

$\mathrm{A}=$ packet data dikirim

\section{Delay (Latency)}

Delay adalah waktu yang dibutuhkan paket untuk mencapai tujuan, karena adanya antrian, atau mengambil rute yang lain untuk menghindari kemacetan yang diperlihatkan pada Tabel 4.

Tabel 4. Kategori dari Delay (Latency)

\begin{tabular}{ccc}
\hline $\begin{array}{c}\text { Kategori } \\
\text { Latensi }\end{array}$ & Besar delay (ms) & Indeks \\
\hline Sangat Bagus & $<150 \mathrm{~ms}$ & 4 \\
\hline Bagus & $\begin{array}{c}150 \mathrm{~ms} \mathrm{~s} / \mathrm{d} 300 \\
\mathrm{~ms}\end{array}$ & 3 \\
\hline $\begin{array}{c}\text { Sedang } \\
\text { ms }\end{array}$ & 2 \\
\hline Jelek & $\begin{array}{c}\mathrm{ms} 450 \\
\mathrm{~ms} \mathrm{~s}\end{array}$ & 1 \\
\hline
\end{tabular}

Delay dapat dicari dengan membagi antara panjang paket (L, packet length (bit/s)) dibagi dengan link bandwith ( $\mathrm{R}$, link bandwith (bit/s)). Pada Tabel 4 diperlihatkan kategori dari latensi dan besar delay.

Untuk mengukur nilai delay digunakan persamaan :

$$
\text { Delay }=\frac{\text { Packet length }}{\text { Link Bandwiadth }}
$$

\section{Jitter atau Variasi Kedatangan Paket}

Jitter diakibatkan oleh variasi-variasi dalam panjang antrian, dalam waktu pengolahan data, dan juga dalam waktu penghimpunan ulang paket-paket di akhir perjalanan jitter yang diperlihatkan pada Tabel 5 .

Tabel 5. Kategori dari Jitter

\begin{tabular}{|ccc}
\hline $\begin{array}{c}\text { Kategori } \\
\text { Jitter }\end{array}$ & Jitter $(\mathbf{m s})$ & Indeks \\
\hline Sangat Bagus & $0 \mathrm{~ms}$ & 4 \\
\hline Bagus & $0 \mathrm{~ms} \mathrm{~s} / \mathrm{d} 75 \mathrm{~ms}$ & 3 \\
\hline
\end{tabular}

\begin{tabular}{ccc}
\hline Sedang & $75 \mathrm{~ms} \mathrm{~s} / \mathrm{d} 125 \mathrm{~ms}$ & 2 \\
\hline Jelek & $\begin{array}{c}125 \mathrm{~ms} \mathrm{~s} / \mathrm{d} \mathrm{225} \\
\mathrm{ms}\end{array}$ & 1 \\
\hline
\end{tabular}

Untuk mengukur nilai Jitter digunakan Persamaan:

$$
\text { jitter }=\frac{\text { total variasi delay }}{\text { total paket yang diterima }}
$$

Total variasi delay $=$ delay $-($ rata-rata delay $)$

\section{Topologi Jaringan Internet}

Topologi jaringan internet antar gedung di Universitas Islam Syekh-Yusuf menggunakan topologi campuran, yaitu topologi star dan mesh seperti ditunjukan pada Gambar 3.

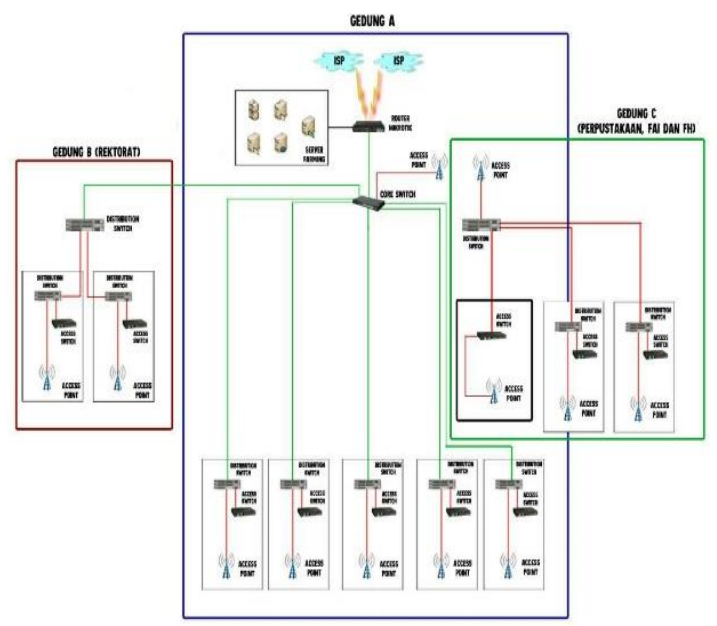

Gambar 3. Topologi Jaringan

\section{Pengukuran Paramater QoS}

Untuk mengukur Jitter, kecepatan download, dan kecepatan upload menggunakan www.speedtest.biznetworks.com. Untuk mengukur delay, throughtput, dan packet loss menggunakan aplikasi Wireshark. Prinsip kerjanya yaitu dengan terhubung terlebih dahulu ke jaringan yang akan diukur.

\section{Pengukuran Jitter}

Pada penelitian ini digunakan website speedtest.biznetworks.com untuk mengukur Jitter. Prinsip kerjanya yaitu dengan terhubung terlebih dahulu ke jaringan yang akan diukur setelah itu membuka website speedtest.biznetworks.com dan mulailah pengukuran . 


\section{Pengukuran Delay, Throughput dan Packet Loss}

Wireshark merupakan salah satu tools atau aplikasi "Network Analyzer" atau Penganalisa Jaringan. Penganalisaan Kinerja Jaringan itu dapat melingkupi berbagai hal, mulai dari proses menangkap paket-paket data atau informasi yang berlalu-lalang dalam jaringan, sampai pada digunakan pula untuk sniffing (memperoleh informasi penting seperti password email, dll). Wireshark sendiri merupakan free tools untuk Network Analyzer yang ada saat ini. Dan tampilan dari wireshark ini sendiri terbilang sangat bersahabat dengan user karena menggunakan tampilan grafis atau GUI (Graphical User Interface).

\section{Hasil dan Pembahasan}

1. Pengukuran Jitter
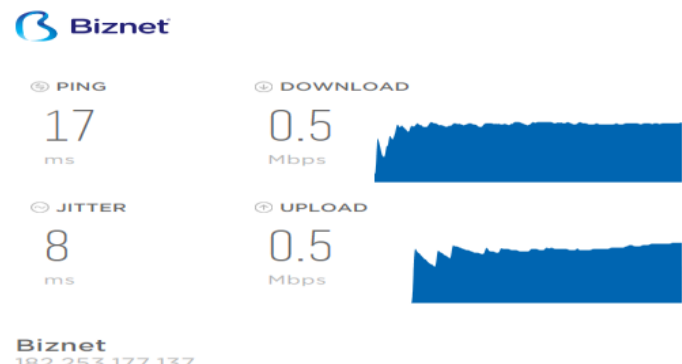

Gambar 4. Pengukuran Jitter

Berdasarkan nilai Jitter sesuai dengan versi TIPHON sebagai standarisasi, untuk kategori Jitter "Sangat Bagus" jika 0 ms, "Bagus" jika 0 ms s/d 75 ms, "Sedang" jika 75 ms s/d 125 ms, dan "Jelek" jika 125 ms s/d 225 ms. Maka hasil nilai Jitter adalah "Bagus" dengan nilai indeks "3".

\section{Pengukuran Throughput}

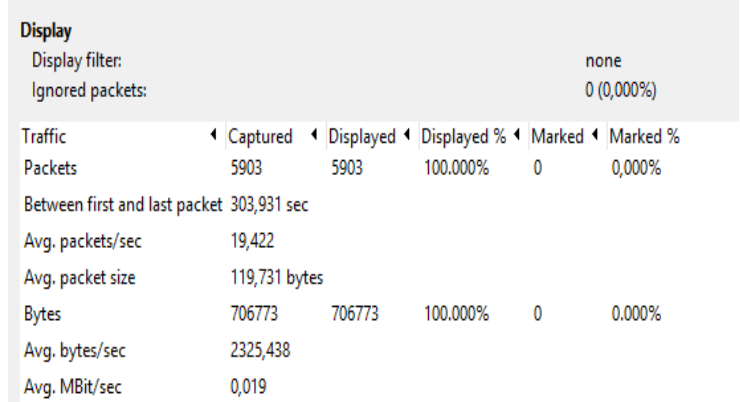

Gambar 5. Pengukuran Throughput

Berdasarkan nilai Throughput sesuai dengan versi TIPHON sebagai standarisasi, untuk kategori Throughput sangat bagus jika presentase
Throughput 100\%, bagus jika presentase Throughput 75\%, sedang jika presentase Throughput $50 \%$ dan jelek jika presentasi Throughput $<25 \%$. Maka, didapat hasil dengan nilai $\frac{706773}{303,31}=2,324,439 \mathrm{MBit} / \mathrm{sec}$, dengan presentase 50\% adalah "Sedang" dengan nilai indeks 2.

\section{Pengukuran Packet Loss}

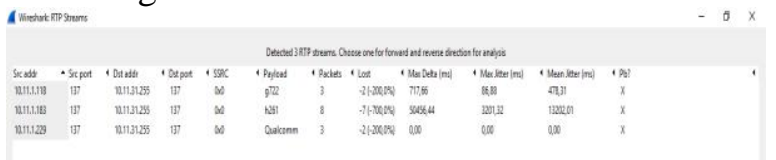

Gambar 6. Pengukuran Packet Loss

Sesuai dengan versi TIPHON sebagai standarisasi, untuk kategori Packet Loss "Sangat Bagus jika 0\%, "Bagus" jika $3 \%$, "Sedang" jika 15\%, dan "Jelek" jika 25\%. Maka didapat nilai "Sangat Bagus" dengan nilai indeks 4.

\section{Pengukuran Delay}

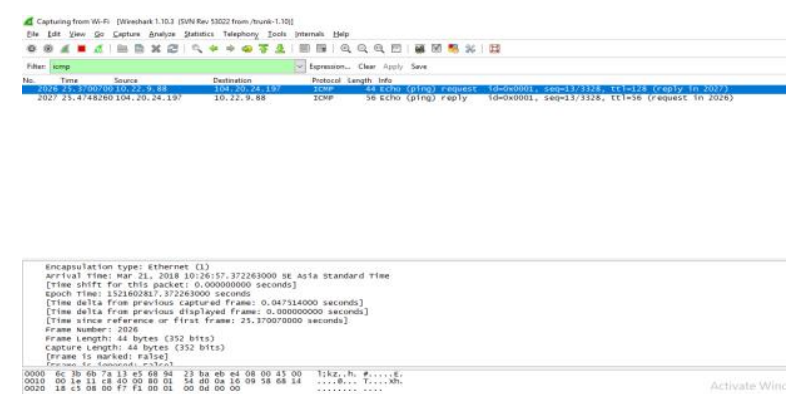

Gambar 7. Pengukuran Delay

Berdasarkan nilai Delay $300 \mathrm{~ms}$ s/d $450 \mathrm{~ms}$, dan jelek jika > $450 \mathrm{~ms}$. sesuai dengan versi TIPHON sebagai standarisasi, umtuk kategori delay sangat bagus jika $<150 \mathrm{~ms}$, bagus jika 150 ms s/d $300 \mathrm{~ms}$, sedang jika Maka didapat nilai "Sangat Bagus" dengan nilai indeks 4.

\section{Kesimpulan}

Dari hasil analisis Quality of Service (QoS) jaringan internet di Universitas Islam SyekhYusuf Tangerang, maka dapat diambil kesimpulan sebagai berikut :

1. Website yang dipakai untuk pengukuran parameter QoS yaitu speedtest.biznetworks.com, dan aplikasi Wireshark.yang terlebih dahulu terhubung kedalam jaringan untuk melakukan pengukuran.

2. Berdasarkan hasil analisa didapatkan hasil setiap parameter adalah jitter sebesar 8 adalah "Bagus" dengan nilai indeks " 3 ", 
throughput 2,325,439 MBit/sec, dengan presentase $50 \%$ adalah "Sedang" dengan nilai indeks 2, packet loss dengan nilai $0 \%$ "Sangat Bagus" dengan nilai indeks 4, dan delay "Sangat Bagus" dengan nilai indeks 4.

\section{Daftar Pustaka}

http://lengaututorial.blogspot.co.id/2017/0/caramenghitung-delay-jaringan.html? $=1$

http://mtsmuh05tamansari.blogspot.co.ic/2014/1 0/makalah-jaringan-komputer.html? $\mathrm{m}=1$

http://ilmukomputer.org/2012/10/25/menghitung -delay-paket-pada-jaringanmenggunakan-wireshark/

Jurnal: Analisis Optimasi Kinerja Quality Of Service Pada Layanan Komunikasi Data Menggubakan NS-2 Di PT.PLN (PERSERO) JEMBER

Jurnal : Analisi Quality Of Service (QoS) Jaringan Internet di SMK TELKOM MEDAN 